Synthesis of Natural

Products and

Potential Drugs

\title{
Synthesis of Eravacycline
}

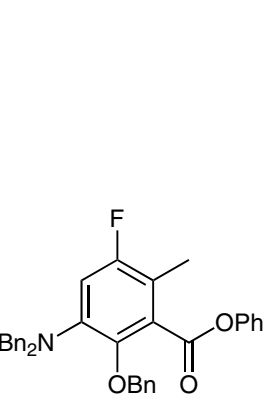

A (1.04 equiv)

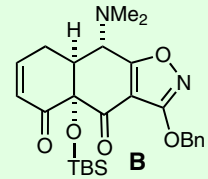

LDA (1.13 equiv) $\mathrm{Et}_{3} \mathrm{~N} \cdot \mathrm{HCl}(0.005$ equiv $)$ THF, $-70{ }^{\circ} \mathrm{C}, 82 \mathrm{~min}$

then add $\mathbf{B}$ ( 1.0 equiv) $-70{ }^{\circ} \mathrm{C}, 52 \mathrm{~min}$ then add LiHMDS ( 0.92 equiv) -70 to $-10^{\circ} \mathrm{C}$ $94 \%(1.085 \mathrm{~mol}$ scale $)$

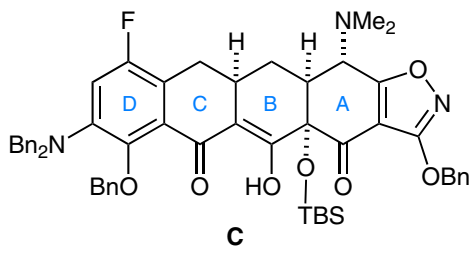

$\mathrm{mp}$ not reported

\section{Key words}

eravacycline

tetracycline antibiotics

Michael-Dieckmann annulation
Significance: Eravacycline is a fully synthetic broad-spectrum antibiotic that has completed phase 2 clinical trials for the treatment of multidrug-resistant bacteria. The key step entails the construction of ring $\mathrm{C}$ by a tandem Michael addition of arene $\mathbf{A}$ to cyclohexenone $\mathbf{B}$ followed by a Dieckmann cyclization to afford pentacycle $\mathbf{C}$ in $94 \%$ yield on a mol scale.
Comment: The versatile Michael-Dieckmann route to tetracyclines was pioneered by Myers and co-workers (J. Am. Chem. Soc. 2008, 130, 17913). A seven-step multigram-scale synthesis of the crystalline cyclohexenone $\mathbf{B}$ has been described: J. D. Brubaker, A. G. Myers Org. Lett. 2007, 9, 3523. Several kilograms of eravacycline were synthesized by the route depicted.

SYNFACTS Contributors: Philip Kocienski 